\title{
Growth Hormone Treatment, Cardiovascular Risk and Autonomic Maturation in Children and Adolescents with Growth Hormone Deficiency or Born Small for Gestational Age
}

\author{
Reiner Buchhorn, Christian Willaschek ${ }^{*}$ \\ Department of Pediatrics, Caritas Krankenhaus, Bad Mergentheim, Germany \\ Email: *christia n.willaschek@ckbm.de
}

How to cite this paper: Buchhorn, R. and Willaschek, C. (2020) Growth Hormone Treatment, Cardiovascular Risk and Autonomic Maturation in Children and Adolescents with Growth Hormone Deficiency or Born Small for Gestational Age. Open Journal of Pediatrics, 10, 12-29.

https://doi.org/10.4236/ojped.2020.101002

Received: December 6, 2019

Accepted: January 16, 2020

Published: January 19, 2020

Copyright $\odot 2020$ by author(s) and Scientific Research Publishing Inc. This work is licensed under the Creative Commons Attribution International License (CC BY 4.0).

http://creativecommons.org/licenses/by/4.0/

(c) (i) Open Access

\begin{abstract}
Introduction: The impact of growth hormone therapy in children with short stature on cardiovascular prognosis seems to be unpredictable from big databases. The enhanced cardiovascular risk in this group of patients may be related to adverse autonomic imprinting by early life stress. Autonomic dysfunction and possible effects of growth hormone therapy on the autonomic nervous system can be measured easily by calculating heart rate variability (HRV) from Holter electrocardiogram monitoring. Methods: We performed HRV analysis prior to growth hormone therapy $(\mathrm{N}=33)$, within the first year of growth hormone therapy between 4 and 10 years of age $(\mathrm{N}=19)$, at least a further HRV measurement between 10 and 15 years $(\mathrm{N}=30)$. Additional measurements were performed before and after cessation of growth hormone therapy $(\mathrm{N}=14)$. Data were compared to untreated pediatric patients with short stature and to age matched healthy controls. Results: Untreated patients with short stature due to growth hormone deficiency or intrauterine growth restriction in early childhood have significantly increased heart rates most of all at night and concomitantly reduced global HRV indicated as Standard Deviation of Normal to Normal Intervals (SDNN). Growth hormone treated adolescents and the untreated patients with short stature show significantly elevated mean heart rates and concomitantly reduced vagus activities measured as reduced Route Mean Square Standard Deviation (RMSSD). After cessation of growth hormone treatment SDNN significantly increases and heart rate decreases to normal values in formerly treated patients with catch-up growth. Conclusion: There is a comparable autonomic dysfunction in treated and untreated children with short stature as an indicator for enhanced cardiovascular risk. After cessation of growth hormone
\end{abstract}


therapy, we found a significant improvement of reduced HRV to normal values.

\section{Keywords}

Growth Hormone, Cardiovascular Risk, Short Stature, Small for Gestational Age, Heart Rate Variability, Autonomic Nervous System, ADHD

\section{Introduction}

Short Stature is associated with an increased cardiovascular mortality [1], most of all in former children with growth hormone deficiency (GHD) [2] and intrauterine growth retardation [3]. Interventions in middle income countries that are aimed at improving birth weight and growth during the first two years seem to improve further growth, schooling and apparently provide some protection from chronic disease in adulthood. But increasing weight and height seem to increase blood pressure in adulthood [4]. However, in children with short stature the impact of growth hormone therapy on cardiovascular mortality seems to be unpredictable. A large European study has been started to proof Safety and Appropriateness of Growth hormone treatment in Europe (SAGhE cohort; http://cordis.europa.eu/search/result de? $\mathrm{q}=$ saghe) in 24,232 patients, most commonly treated for isolated growth failure (53\%), Turner syndrome (13\%) and growth hormone deficiency linked to neoplasia (12\%). The results announced for 2015 have not yet been published but probably will confirm the known increased cardiovascular risk in patients with short stature. Recently published data from the GeNeSIS observational program, which were collected from 1999 to 2015, support the safety of pediatric growth hormone treatment [5]. However, according to the low cardiovascular risk in "otherwise healthy children" nearly all growth hormone treated children will not reach cardiovascular endpoints like myocardial infarction, sudden cardiac death or stroke in childhood. Therefore, the impact of growth hormone (GH) therapy on cardiovascular mortality in later adult life remains unclear by observational studies. Investigating heart rate variability (HRV) as a well established surrogate parameter for cardiovascular risk seems to be informative.

$\mathrm{GH}$ replacement improves cardiovascular health in adults suffering from growth hormone deficiency [6]. However, comorbidities related to the cardiovascular system are one of the most prevalent in adults with acromegaly due to $\mathrm{GH}$ excess [7]. The pathophysiology is not well understood but intense sympathetic nerve activity in patients with untreated growth hormone deficiency [8] seems to be the link between the autonomic nervous system and cardiovascular risk.

By measuring HRV, which is a non-invasive surrogate parameter to predict the cardiovascular risk, we achieve insight into the maturation process of the autonomic nervous system in childhood. HRV increases from infancy to adolescence due to vagus maturation. In adults HRV declines with increasing age. The 
maturation process in childhood seems to be influenced by early life stress in and ex utero, which is called autonomic imprinting:

1) Children with GHD show a blunted autonomous response to clonidine indicating $\alpha 2$-adreno receptor sub sensitivity. This finding is prior to the start of growth hormone treatment. Similar but less severe blunted autonomous response to clonidine was found in children born small for gestational age (SGA) [9].

2) Not short stature itself, but rather the underlying pathophysiology seem to be the cause for reduced HRV in children with height below the third percentile. These high risk children-having experienced an adverse autonomic imprinting in utero or infancy (SGA, congenital heart disease and congenital syndromes) - have the highest risk for 'stress diseases' and an enhanced cardiovascular mortality in later life [10].

As children with diagnosis of GHD and children with SGA history are not analised separately, for better reading we choose to consider this group as Symptomatic Short Stature (SySS).

\section{Methods}

\subsection{Ethical Statement}

The FDA issued a Safety Alert in August 2011, reporting on a French study concluding that people with certain types of short stature treated with recombinant human growth hormone during childhood and who were then followed over a long period of time, were at a small increased risk of death when compared to individuals from the general population of France. This increased mortality rate is related to cardiovascular events [11] and/or stroke [12]. As shown in our previous work [9] [10] the increased risk for cardiac events seems to be due to a phenomenon called autonomic imprinting and is pathophysiologically explained by blunting of the central $\alpha 2$-adreno receptor. The underlying normal values of these projects have been generated during our "normal values heart rate variability project". Therefore data of patients, who attended our outpatient clinic for exclusion of cardiac arrhythmia were analysed retrospectively. The retrospective analysis was approved by the ethical board of our county medical chamber (Landesärztekammer Baden Württemberg, Stuttgart 2012) and recently published [13].

We routinely communicate this enhanced cardiovascular risk to all parents prior to GH treatment (oral communication) and offer monitoring of cardiovascular risk by 24-hour Holter electrocardiogram (ECG) and NT-BNP measurements as part of routine blood tests for short stature. No additional punctures were necessary. We received informed consent from nearly all parents of children with growth failure, but we certainly disregard performing these examinations if the parents refuse. All parents and patients (if appropriate according to their age) enrolled in this analysis have given oral informed consent for the procedure, data storage and publication. 
Because Holter ECG is a completely non invasive standard procedure and does not bear any additional clinical risk we considered oral consent to be sufficient.

\subsection{Diagnosing GHD}

For short stature children, who met clinical, auxological and laboratory criteria, bone age was assessed using the Method of Greulich and Pyle and GH stimulation testing was performed with two independent drugs.

\subsection{Clonidine Testing}

GHD was diagnosed using standard Clonidine testing. Patients with short stature and suspected GHD spent a day at our clinic. Clonidine stimulation was performed with an oral dose of $0.15 \mathrm{mg} / \mathrm{m}^{2}$ body surface area. Blood samples for growth hormone measurements were taken 15 minutes before and 45, 60, 90 and 120 minutes after Clonidine application. Patients were monitored closely for heart rate and blood pressure. Transient arterial hypotension was treated appropriately with $10 \mathrm{ml} / \mathrm{kg}$ body weight normal saline bolus therapy. For improvement of patients' safety 24-hour Holter ECG were additionally performed [9].

\subsection{Arginine Testing}

Arginine was used as an independent second test for GHD. A single dose of $0.5 \mathrm{~g}$ per $\mathrm{kg}$ body weight was given i.v. GH was analysed from samples before and 15, 30, 45, 60, 90 and $120 \mathrm{~min}$. after Arginine infusion.

A GH peak $<8 \mu \mathrm{g} / \mathrm{L}(\mathrm{ng} / \mathrm{ml})$ in both tests was considered to diagnose GHD.

\subsection{Analysis of Heart Rate Variability}

To improve the safety of growth hormone treatment in childhood during the maturation of the autonomic nervous system we analysed 24-hour HRV by Holter ECG monitoring as described in detail in our former articles [9] [10].

Fundament of every HRV data analysis is a group of successive normal RR intervals in sinus rhythm (so called $\mathrm{NN}$ intervals in comparison to RR intervals in cardiac arrhythmia) in 24 hours.

Measurement and interpretation of HRV parameters in the current sample were standardized according to the Task Force Guidelines [9] [14]. Cardiac autonomic functioning was measured by 24-hour Holter 12 bit digital ECG (Reynolds Pathfinder II, Spacelabs, Germany; 1024 scans/sec). Daytime and night-time periods were defined according to patient protocols. All Holter recordings were reviewed by the same experienced cardiologists (RB and CW) and were edited to validate the systems QRS labelling. Measures of HRV were calculated employing only normal-to-normal intervals. QRS-complexes classified as noise were excluded from the data. A minimum of 23 hours of analysable data and minimally $95 \%$ of analysable $\mathrm{NN}$ intervals were required for data to be included. For time domain measures, mean RR interval, resulting heart rate and 
the following HRV parameters were calculated.

For didactic reasons in this study we focus on the statistical analysis of the following 4 parameters, which are briefly outlined below:

1) Heart rate: The easiest but very important HRV parameter is the average sinus rhythm heart rate, since all other parameters are significantly affected by the heart rate.

2) SDNN: Standard deviation of all normal to normal RR intervals in a time frame. This global HRV parameter represents the overall variability of the autonomic nervous system.

3) rMSSD: Square root of the arithmetic mean of the squared deviation of successive normal RR intervals in a time frame. This parameter is mainly influenced by the parasympathetic nervous system.

4) pNN50: Number of pairs of adjacent NN intervals differing by more than $50 \mathrm{~ms}$ divided by the total number of all NN intervals multiplied by 100. This parameter is mainly influenced by the parasympathetic nervous system.

For frequency domain measures, beat-to-beat fluctuations were transformed to the frequency domain using Fast Fourier Transformation. Spectral power was determined over three frequency regions of interest: Very low frequency (VLF < $0.04 \mathrm{~Hz}$ ), low frequency (LF, $0.04-0.15 \mathrm{~Hz}$ ) and high frequency (HF, $0.15-0.4$ $\mathrm{Hz}$ ) with derived HF/LF ratio. Low frequency power reflects mostly sympathetic activity, high frequency power vagal tone.

\subsection{Subjects}

Data were collected during outpatient visits from March 2015 to July 2018.

We performed HRV analysis prior to growth hormone therapy (Symptomathic Short Stature children untreated; $\mathrm{N}=33 ; 17$ females, 16 males), within the first year of growth hormone therapy between 4 and 10 years of age (children treated, $\mathrm{N}=19$; 10 female, 9 males, growth hormone dose $=0.7 \pm 0.2 \mathrm{mg} /$ day), at least a further HRV measurement between 10 and 15 years (adolescents treated, $\mathrm{N}=30$; 12 females, 18 males, growth hormone dose $=1.4 \pm 0.5 \mathrm{mg} /$ day) and one measurement after cessation of growth hormone therapy $(\mathrm{N}=14$, mean age 13.25). Ten children with short stature below 3rd percentile ( 3 females, 7 males) who had a late diagnosis or whose parents refused GH therapy are used as an untreated control group with an age between 10 and 16 years. For our analysis we only used data from children with the diagnosis growth hormone deficiency or small for gestational age. Patients were healthy in any other condition except for a remarkable incidence of Attention-Deficit/Hyperactivity Disorder (ADHD) (Table 1(a), Table 1(b)). Over all 22 of 106 patients with SySS (children and adolescents) had diagnose of ADHD. Testing for ADHD in most cases was done in a near by outpatient clinic for pediatric psychiatry.

Age matched healthy children were collected from our own healthy control group published in 2014 [13]. Children with a body mass index above $96 \%$ and height below $3 \%$ had been excluded from this group of healthy children. 
Table 1. (a) Clinical data and laboratory healthy controls and patients groups (children);

(b) Clinical data and laboratory healthy controls and patients groups (adolescents).

(a)

\begin{tabular}{|c|c|c|c|c|}
\hline \multirow[t]{3}{*}{ Parameter } & \multirow{3}{*}{$\begin{array}{l}\text { Healthy } \\
\text { Control }\end{array}$} & \multicolumn{3}{|c|}{ Symptomatic Short Stature (Children) } \\
\hline & & \multirow{2}{*}{$\begin{array}{c}\text { Growth Hormone } \\
\text { Therapy } \\
\text { Mean } \pm \mathrm{SD}\end{array}$} & \multicolumn{2}{|c|}{ Untreated } \\
\hline & & & Mean \pm SD & P-value \\
\hline & $\mathrm{N}=49$ & $\mathrm{~N}=19$ & \multicolumn{2}{|c|}{$\mathrm{N}=33$} \\
\hline Age [years] & $6.6 \pm 1.9$ & $6.9 \pm 1.8$ & $5.8 \pm 2.4$ & n.s. \\
\hline female/male & & $10 / 9$ & $16 / 17$ & n.s. \\
\hline GHD/SGA & & $11 / 8$ & $9 / 30$ & n.s. \\
\hline ADHD & & 3 & 4 & n.s. \\
\hline Birth weight $[\mathrm{g}]$ & & $2281 \pm 845$ & $2437 \pm 1069$ & n.s. \\
\hline Height $[\mathrm{cm}]$ & & $113.3 \pm 13.9$ & $103.2 \pm 14.6^{*}$ & 0.014 \\
\hline Height SDS & & $-1.9 \pm 1.0$ & $-2.5 \pm 0.8^{*}$ & 0.0295 \\
\hline $\mathrm{BMI}\left[\mathrm{kg} / \mathrm{m}^{2}\right]$ & & $14.6 \pm 1.3$ & $14.8 \pm 1.4$ & n.s. \\
\hline BMI Percentile [\%] & & $27 \pm 22$ & $27 \pm 23$ & n.s. \\
\hline $\begin{array}{c}\text { NT-Pro-BNP } \\
{[0.0-85.0 \mathrm{pg} / \mathrm{ml}]}\end{array}$ & & $84 \pm 72$ & $169 \pm 123^{*}$ & 0.026 \\
\hline $\begin{array}{c}\text { IgF } 1[57-305 \mu \mathrm{g} / \mathrm{ml}] \\
\text { before treatment }\end{array}$ & & $55.5 \pm 31.9$ & & n.s. \\
\hline $\begin{array}{c}\text { IgFBP } 3[2100-5600 \mu \mathrm{g} / \mathrm{ml}] \\
\text { before treatment }\end{array}$ & & $2348 \pm 793$ & & n.s. \\
\hline IgF $1[57-305 \mu \mathrm{g} / \mathrm{ml}]$ & & $191 \pm 104$ & $87 \pm 67^{* * *}$ & 0.0005 \\
\hline IgFBP $3[2100-5600 \mu \mathrm{g} / \mathrm{ml}]$ & & $3927 \pm 983$ & $2922 \pm 1050^{\star *}$ & 0.0057 \\
\hline
\end{tabular}

(b)

\begin{tabular}{|c|c|c|c|c|}
\hline \multirow[t]{4}{*}{ Parameter } & \multirow[t]{2}{*}{$\begin{array}{l}\text { Healthy } \\
\text { Control }\end{array}$} & \multicolumn{3}{|c|}{ Symptomatic Short Stature (Adolescents) } \\
\hline & & $\begin{array}{c}\text { Growth Hormone } \\
\text { Therapy }\end{array}$ & Untrea & \\
\hline & \multirow[t]{2}{*}{$\mathrm{N}=58$} & $\mathrm{~N}=30$ & \multicolumn{2}{|c|}{$\mathrm{N}=10$} \\
\hline & & Mean \pm SD & Mean \pm SD & $\mathrm{P}$-value \\
\hline Age [years] & $12.8 \pm 1.7$ & $13.0 \pm 2.0$ & $13.1 \pm 2.1$ & n.s. \\
\hline female/male & & $12 / 18$ & $3 / 7$ & n.s. \\
\hline GHD/SGA & & $23 / 7$ & $2 / 8$ & n.s. \\
\hline ADHD & & 9 & 6 & n.s. \\
\hline Height $[\mathrm{cm}]$ & & $149.6 \pm 12.1$ & $140.7 \pm 10.8^{*}$ & 0.045 \\
\hline Height SDS & & $-1.3 \pm 0.8$ & $-2.1 \pm 0.7^{\star \star}$ & 0.0039 \\
\hline $\mathrm{BMI}\left[\mathrm{kg} / \mathrm{m}^{2}\right]$ & & $18.9 \pm 2.6$ & $20.3 \pm 4.2$ & n.s. \\
\hline BMI Percentile [\%] & & $46 \pm 29$ & $57 \pm 36$ & n.s. \\
\hline $\begin{array}{c}\text { NT-Pro-BNP } \\
{[0.0-85.0 \mathrm{pg} / \mathrm{ml}]}\end{array}$ & & $34 \pm 21$ & $44 \pm 49$ & n.s. \\
\hline IgF $1[57-305 \mu \mathrm{g} / \mathrm{ml}]$ & & $414.9 \pm 155.9$ & $138.0 \pm 91.1^{* *}$ & 0.0011 \\
\hline IgFBP $3[2100-5600 \mu \mathrm{g} / \mathrm{ml}]$ & & $5167 \pm 933$ & $3456 \pm 861^{* *}$ & 0.0017 \\
\hline
\end{tabular}

GHD: Growth Hormone Deficiency; SGA: Small for Gestational Age; ADHD: Attention-deficit/hyperactivity disorder; BMI: Body mass Index; IgF1: Insulin like growth factor 1; IgFPB3: Insulin like growth factor 1 binding protein; NT-Pro-BNP: N-terminal brain natriuretic peptide, n.s.: not significant. Unpaired $\mathrm{t}$-test between treated and untreated patients. ${ }^{*} \mathrm{P}$-value $<0.05 ;{ }^{* *} \mathrm{P}$-value $<0.01 ;{ }^{* * *} \mathrm{P}$-value $<0.001$. 


\subsection{Statistical Analysis}

Groups were compared with controls by means, standard deviations and unpaired t-testing. For the comparison of HRV before and after cessation of GH therapy we used paired t-test as these subjects were identical. P-values below 0.05 were considered as statistically significant. From anthropometric data percentile values and body mass index (BMI) have been calculated according to percentile data by Kromeyer-Hauschild et al.

\section{Results}

Routine clinical data are displayed in Table 1(a) and Table 1(b). The groups of $\mathrm{GH}$ treated and untreated patients in early childhood and during adolescence do not show significantly different ages. The two patient groups are compared to an age matched healthy control group at the age of $6.6 \pm 1.9$ years (Table $1(\mathrm{a})$ ) and $12.8 \pm 1.7$ years (Table $1(\mathrm{~b})$ ) on average. Birth weights are reduced on average but not significantly different between treated and untreated patients. Heights are $10 \mathrm{~cm}$ higher in treated children and $9 \mathrm{~cm}$ higher in treated adolescents. Insulin like growth factor 1 (IGF 1) and the insulin like growth factor binding protein (IGFBP3) are significantly higher due to growth hormone therapy. Remarkably these values were in the lower normal range before the start of GH therapy (Table 1(a)). Body mass indices are normal and not significantly different between treated and untreated patients. No patients suffer from obesity. NT-Pro-BNP is slightly elevated above normal values in untreated children and significantly higher compared to growth hormone treated children.

HRV data are displayed in Table 2(a), Table 2(b). Untreated in children with SySS in early childhood show significantly increased heart rates most of all at night and concomitantly reduced global HRV indicated as SDNN. The smaller group of growth hormone treated children $(\mathrm{N}=19)$ does not show significantly different HRV data compared to healthy controls but also to age matched untreated children (these non significant p-values are not illustrated in the table).

$\mathrm{GH}$ treated adolescents and the untreated adolescents with symptomatic short stature show significantly elevated mean heart rates and concomitantly reduced vagus activities measured as reduced RMSSD as well as reduced pNN50 and high frequency power. Global HRV indicated as SDNN is significantly reduced in adolescents with symptomatic short stature either in treated or in untreated patients.

Graphic illustrations of single HRV values are displayed in Figure 1(a) and Figure 1(b). Patients with SySS are showing elevated heart rates and reduced HRV (RMSSD and SDNN) with increasing age independent of the treatment with growth hormone.

Figure 1(a) HRV parameters Heart Rate, RMSSD and SDNN of children with and without GH treatment. Heart rate is higher and SDNN is lower in untreated children compared to GH treatment. Compared to healthy controls heart rate is higher and HRV expressed by SDNN and RMSSD is lower in both groups of short patients. 
Table 2. (a) HRV analysis in treated and untreated children with symptomatic short stature compared to age matched healthy children; (b) HRV analysis in treated and untreated adolescents with symptomatic short stature compared to age matched controls.

(a)

\begin{tabular}{|c|c|c|c|c|c|}
\hline \multirow[t]{3}{*}{ Parameter } & \multirow[t]{3}{*}{$\begin{array}{l}\text { Healthy } \\
\text { Control }\end{array}$} & \multicolumn{4}{|c|}{ Symptomatic Short Stature (Children) } \\
\hline & & \multicolumn{2}{|c|}{$\begin{array}{c}\text { Growth Hormone } \\
\text { Therapy }\end{array}$} & \multicolumn{2}{|c|}{ Untreated } \\
\hline & & Mean \pm SD & $\mathrm{P}$-value & Mean \pm SD & $\mathrm{P}$-value \\
\hline & $\mathrm{N}=49$ & \multicolumn{2}{|c|}{$\mathrm{N}=19$} & \multicolumn{2}{|c|}{$\mathrm{N}=33$} \\
\hline Age [years] & $6.6 \pm 1.9$ & \multicolumn{2}{|c|}{$6.9 \pm 1.8$} & \multicolumn{2}{|c|}{$5.8 \pm 2.4$} \\
\hline Heart Rate [bpm] & $92.9 \pm 9.2$ & $96.2 \pm 8.9$ & n.s. & $97.8 \pm 9.5^{*}$ & 0.0218 \\
\hline HR day $[\mathrm{bpm}]$ & $104.9 \pm 10.7$ & $108.2 \pm 10.0$ & n.s. & $108.4 \pm 11.6$ & n.s. \\
\hline HR night [bpm] & $79.2 \pm 9.0$ & $82.6 \pm 8.7$ & n.s. & $83.8 \pm 8.9^{*}$ & 0.0345 \\
\hline RMSSD [ms] & $40.3 \pm 10.6$ & $35.8 \pm 11.3$ & n.s. & $36.8 \pm 8.8$ & n.s. \\
\hline pNN50 [\%] & $21.6 \pm 10.2$ & $19.4 \pm 11.5$ & n.s. & $20.4 \pm 9.1$ & n.s. \\
\hline SDNN [ms] & $132.7 \pm 32.6$ & $123.5 \pm 29.3$ & n.s. & $115.6 \pm 24.6^{*}$ & 0.0138 \\
\hline Total Power $\left[\mathrm{ms}^{2}\right]$ & $4249 \pm 1997$ & $4296 \pm 1997$ & n.s. & $3810 \pm 1597$ & n.s. \\
\hline Very Low Frequency $\left[\mathrm{ms}^{2}\right]$ & $2229 \pm 1235$ & $2223 \pm 1268$ & n.s. & $2074 \pm 1161$ & n.s. \\
\hline Low Frequency $\left[\mathrm{ms}_{2}\right]$ & $1175 \pm 599$ & $1173 \pm 653$ & n.s. & $991 \pm 445$ & n.s. \\
\hline High Frequency $\left[\mathrm{ms}^{2}\right]$ & $738 \pm 290$ & $768 \pm 695$ & n.s. & $639 \pm 280$ & n.s. \\
\hline
\end{tabular}

(b)

\begin{tabular}{cccccc}
\hline Parameter & $\begin{array}{c}\text { Healthy } \\
\text { Control }\end{array}$ & \multicolumn{2}{c}{ Symptomatic Short Stature (Adolescents) } \\
& & \multicolumn{3}{c}{$\begin{array}{c}\text { Growth Hormone } \\
\text { Therapy }\end{array}$} & Untreated \\
\cline { 2 - 6 } & $\mathrm{N}=58$ & $\mathrm{~N}=30$ & $\mathrm{~N}=10$ \\
\hline Age [years] & $12.8 \pm 1.7$ & $13.0 \pm 2.0$ & $13.1 \pm 2.1$ & \\
Heart Rate [bpm] & $80.8 \pm 8.7$ & $85.5 \pm 7.5^{*}$ & 0.013 & $88.72 \pm 10.5^{* *}$ & 0.0119 \\
HR day [bpm] & $89.4 \pm 14.6$ & $94.2 \pm 7.5$ & n.s. & $98.0 \pm 12.4$ & n.s. \\
HR night [bpm] & $67.0 \pm 8.4$ & $73.2 \pm 9.9^{* *}$ & 0.0028 & $74.1 \pm 9.2^{*}$ & 0.0169 \\
RMSSD [ms] & $47.4 \pm 12.2$ & $38.5 \pm 11.7^{* *}$ & 0.0015 & $37.2 \pm 13.8^{*}$ & 0.0119 \\
pNN50 [\%] & $27.1 \pm 10.5$ & $19.6 \pm 11.0^{* *}$ & 0.0029 & $19.4 \pm 11.5$ & n.s. \\
SDNN [ms] & $181.1 \pm 44.9$ & $148.1 \pm 38.0^{* * *}$ & 0.0009 & $138.5 \pm 25.8^{* *}$ & 0.005 \\
Total Power [ms ${ }^{2}$ ] & $6551 \pm 3096$ & $5322 \pm 2365$ & n.s. & $4954 \pm 3272$ & n.s. \\
Very Low Frequency [ms ${ }^{2}$ ] & $3949 \pm 2549$ & $3079 \pm 2549$ & n.s. & $2671 \pm 2222$ & n.s. \\
Low Frequency [ms ${ }^{2}$ ] & $1676 \pm 616$ & $1494 \pm 762$ & n.s. & $1341 \pm 800$ & n.s. \\
High Frequency [ms ${ }^{2}$ ] & $857 \pm 331$ & $674 \pm 286^{*}$ & 0.0133 & $848 \pm 782$ & n.s. \\
\hline
\end{tabular}

HR: Heart Rate; SDNN: Standard deviation of all NN intervals; RMSSD: The square root of the mean of the sum of the squares of differences between adjacent NN intervals; pNN50: Number of pairs of adjacent NN intervals differing by more than $50 \mathrm{~ms}$ divided by the total number of all NN intervals; TP: Total Power; VLF: Very low frequency power; LF: Low frequency power; HF: High frequency power; HF/LF: Ratio HF to LF. n.s.: not significant. Unpaired t-test between Healthy Control and treated/untreated patients. Comparing treated to untreated patients was not significant. ${ }^{*} \mathrm{P}$-value $<0.05 ;{ }^{* *} \mathrm{P}$-value $<0.01 ;{ }^{* * *} \mathrm{P}$-value $<0.001$. 


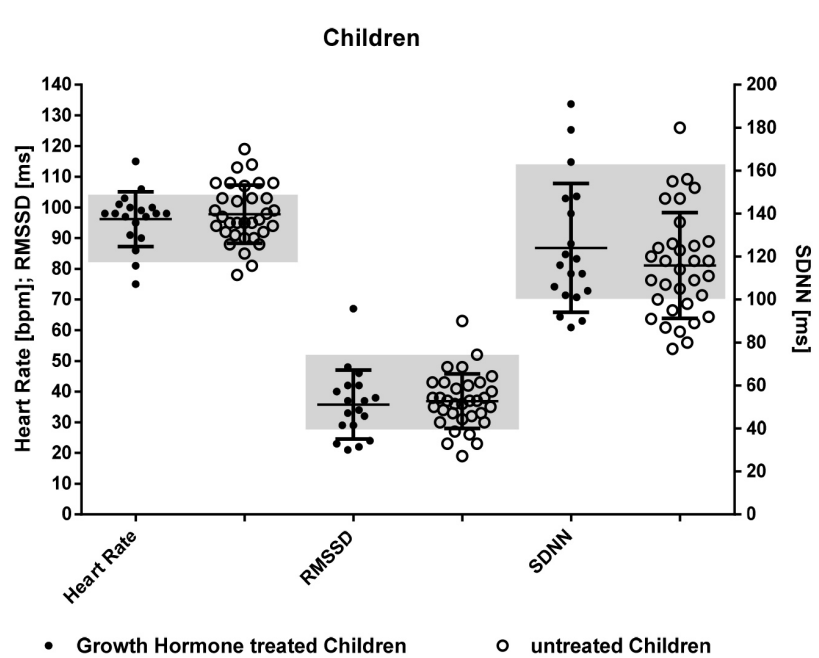

(a)

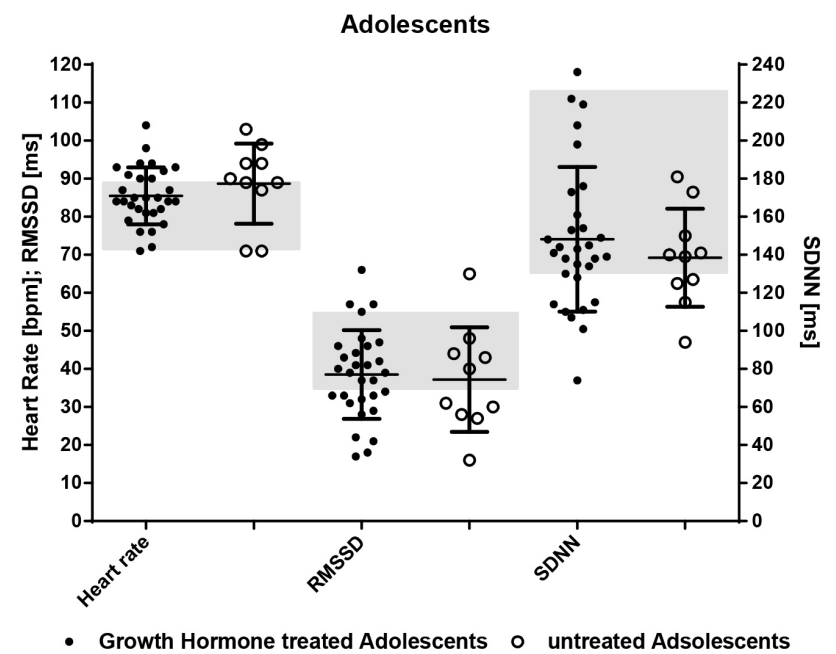

(b)

Figure 1. 24 hours heart rate variability in growth hormone treated and untreated children with short stature due to growth hormone deficiency and intrauterine growth retardation.

Figure 1(b) HRV parameters Heart Rate, RMSSD and SDNN of adolescents with and without GH treatment. Heart rate is higher and SDNN is lower in untreated adolescents compared to growth hormone treatment. Compared to healthy controls heart rate is higher and HRV expressed by SDNN and RMSSD is lower in both groups of short patients.

However after cessation of growth hormone treatment there is a significant improvement of HRV illustrated by lower heart rates and higher global HRV measured as SDNN (Table 3).

The impact of recombinant human growth hormone therapy on the autonomic nervous system in children with SySS is illustrated in Figure 2. It shows the age dependent maturation of global HRV measured as SDNN in the five patients groups compared to the healthy control children. Children and adolescents have significantly reduced SDNN independent from growth hormone treatment.

Figure 2 SDNN of GH treated and untreated patients at different ages and after cessation of growth hormone therapy. SDNN is reduced compared to healthy controls but improves after cessation of GH therapy.

After cessation of GH treatment SDNN increases significantly and heart rate decreases to normal values in former treated patients with catch up growth (Table 3, Figure 2). The circadian pattern of heart rate illustrated in Figure 3 shows that heart rate decreases after cessation of growth hormone at night by 8 beats per minute. We have no data from young adults with GHD or born SGA without growth hormone treatment in childhood to compare them.

Figure 3 Heart rate of adolescent patients during GH therapy and after cessation. Heart rate at night decreases after cessation of growth hormone therapy by 8 beats per minute. 
Table 3. 24 hour HRV in a group of growth hormone treated adolescents before and after cessation of therapy $(\mathrm{N}=14)$.

\begin{tabular}{|c|c|c|c|}
\hline Parameter & $\begin{array}{c}\text { Adolescents during } \\
\text { Growth Hormone Therapy } \\
\qquad \mathrm{n}=14\end{array}$ & \multicolumn{2}{|c|}{$\begin{array}{l}\text { Same Adolescents } \\
\text { after Cessation } \\
\mathrm{n}=14\end{array}$} \\
\hline Age [years] & $17.2 \pm 2.1$ & & \\
\hline female/male & $9 / 5$ & & \\
\hline GHD/SGA & $11 / 3$ & & \\
\hline ADHD & 4 & & \\
\hline Birth weight $[\mathrm{g}]$ & $2779 \pm 972$ & & \\
\hline Height $[\mathrm{cm}]$ & $161.3 \pm 8.6$ & & \\
\hline Height SDS & $-1.44 \pm 0.59$ & & \\
\hline $\mathrm{BMI}\left[\mathrm{kg} / \mathrm{m}^{2}\right]$ & $21.3 \pm 2.8$ & & \\
\hline \multirow[t]{2}{*}{ BMI Percentile [\%] } & $53 \pm 28$ & & \\
\hline & Mean \pm SD & Mean \pm SD & P-value \\
\hline Heart Rate [bpm] & $84.9 \pm 6.2$ & $79.4 \pm 8.5^{\star}$ & 0.048 \\
\hline HR day [bpm] & $93.6 \pm 6.6$ & $88.8 \pm 10.2$ & \\
\hline HR night $[\mathrm{bpm}]$ & $71.8 \pm 6.8$ & $64.3 \pm 7.0^{* *}$ & 0.0013 \\
\hline RMSSD [ms] & $39.6 \pm 9.9$ & $42.4 \pm 11.5$ & \\
\hline pNN50 [\%] & $20.6 \pm 9.3$ & $22.3 \pm 10.3$ & \\
\hline SDNN [ms] & $150.6 \pm 27.2$ & $180.6 \pm 33.8^{* *}$ & 0.0018 \\
\hline Total Power $\left[\mathrm{ms}^{2}\right]$ & $5019 \pm 1845$ & $5757 \pm 2582$ & \\
\hline Very Low Frequency $\left[\mathrm{ms}^{2}\right]$ & $2865 \pm 1144$ & $3388 \pm 1717$ & \\
\hline Low Frequency $\left[\mathrm{ms}^{2}\right]$ & $1377 \pm 655$ & $1596 \pm 774$ & \\
\hline High Frequency $\left[\mathrm{ms}^{2}\right]$ & $698 \pm 213$ & $707 \pm 267$ & \\
\hline HF/LF Ratio & $0.558 \pm 0.204$ & $0.488 \pm 0.211$ & \\
\hline
\end{tabular}

HR: Heart Rate; SDNN: Standard deviation of all NN intervals; RMSSD: The square root of the mean of the sum of the squares of differences between adjacent NN intervals; pNN50: Number of pairs of adjacent NN intervals differing by more than $50 \mathrm{~ms}$ divided by the total number of all NN intervals; HF/LF: Ratio HF to LF. paired t-test before and after cessation of growth hormone therapy. ${ }^{\star} \mathrm{P}$-value $<0.05$; ${ }^{*} \mathrm{P}$-value $<0.01$; ${ }^{* * *}$ P-value $<0.001$.

\section{Discussion}

\subsection{HRV Analysis for Assessment of Autonomic Maturation in Pediatric Patients}

Children with short stature have enhanced cardiovascular risk in later life probably due to adverse autonomic imprinting by early life stress [8]. As recently shown adverse autonomic imprinting seems to be related to intrauterine growth retardation, congenital syndromes, congenital heart defects and GHD [8]. Autonomic dysfunction is displayed by reduced HRV which can be easily measured by 24-hour Holter ECG monitoring [11].

Cardiovascular risk stratification by HRV analysis is well established. Lower HRV indicates a significantly higher cardiovascular mortality [12] [15]. Pediatric 


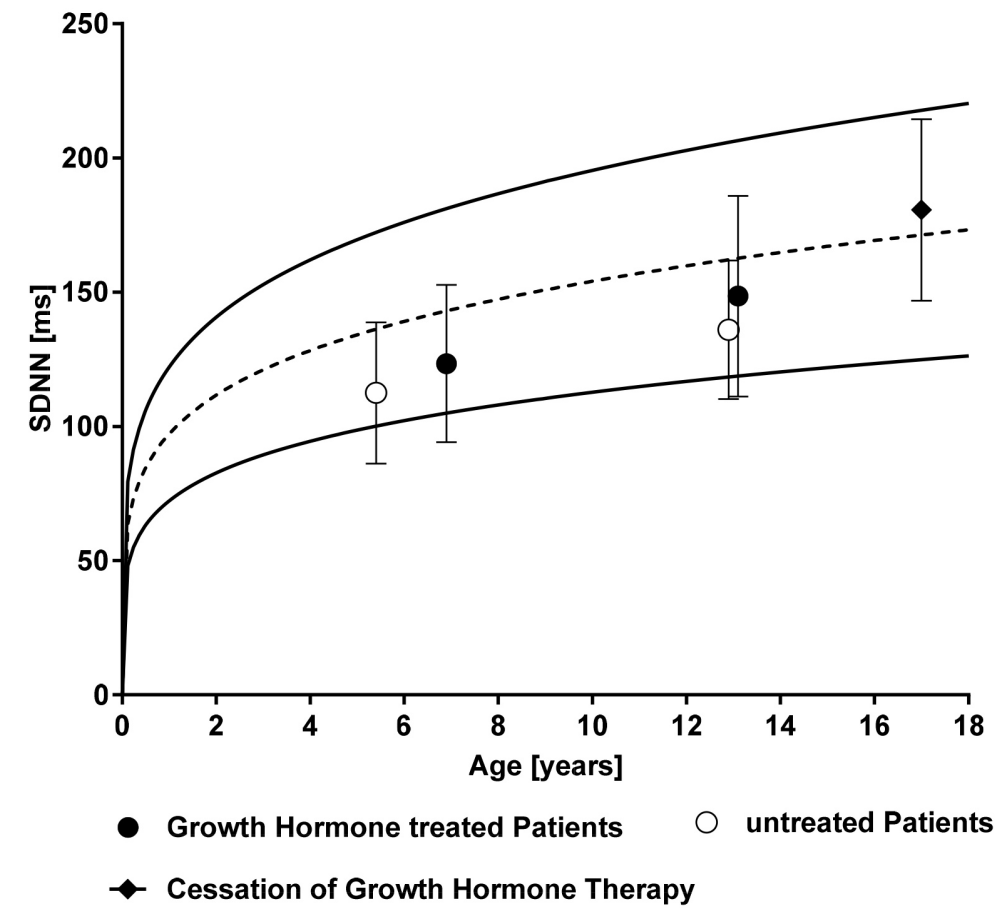

Figure 2. Global 24 hours heart rate variability indicated as SDNN values in treated and untreated children with short stature due to growth hormone deficiency and intrauterine growth retardation and after cessation of growth hormone therapy. Median (dotted) and 95\% interval (solid) lines from age matched healthy control children.

studies focused on children with intrauterine growth restriction and found significantly reduced HRV [16] [17] [18]. In later life adults with extremely low birth weight have reduced HRV [19] [20].

Reduced HRV may indicate intense sympathetic nerve activity as shown in adults with hypopituitarism by muscle sympathetic nerve activity analysis (MSNA) [7]. However reduced HRV—-most of all measured by low rMSSD, pNN50 and high frequency power-may also indicate a loss of the "vagal brake" with important implication on cardiovascular risk [21], cardiac arrhythmia [22], neurocognition [23] and social engagement [24].

In children vagal withdrawal is related to low birth weight and precedes the development of hypertension and other cardio metabolic disease in later childhood [15]. Summarizing these aspects vagus maturation from infancy to adolescence is the hallmark of children's autonomic nervous system and in our view the most important therapeutic target with measurable endpoints in childhood. Observational studies are most likely to fail because they did not provide follow up to later adult age when cardiovascular disease would possibly occur.

\subsection{Autonomic Dysfunction Gets More Pronounced from Childhood to Adolescence}

In our analysis we found significantly reduced HRV in untreated children with SySS but also in those adolescents treated with GH and catch up growth between 


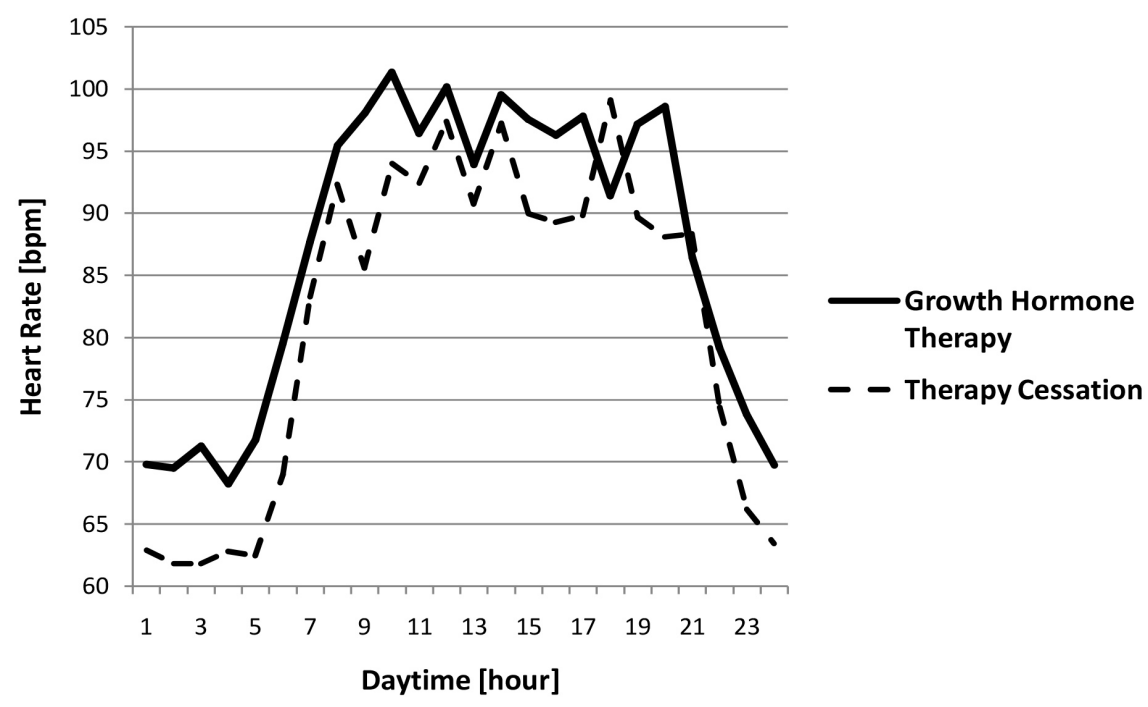

Figure 3. Circadian pattern of heart rate in growth hormone treated adolescents before and after cessation of the therapy given in the evening before sleeping.

10 and 16 years of age. In early childhood between 4 and 10 years of age, HRV is not significantly different in GH treated children compared to healthy controls (Table 2). This may be related to methodical uncertainties as the GH treated group is smaller and older compared to the untreated children (Table 1(a), Table $1(b)$ ) and the age related increase of HRV is more pronounced in early childhood.

\subsection{NT-Pro-BNP Measurement Does Not Seem to Be Informative in Our Cohort}

However, referring to endocrine parameters in early childhood NT-Pro-BNP is significantly higher in untreated children with concomitantly lower IGF-1 and IGFBP3 values but normal in GH treated children with higher IGF-1 and IGFBP3. This may be related to a beneficial effect of growth hormone on NT-Pro-BNP values. These data are in accordance with adult studies: As shown in GH deficient adults NT-pro-BNP decreases after GH replacement [25] without any changes of cardiac mass and function measured by magnetic resonance imaging [26]. Elevated NT-Pro-BNP values most of all in children with intrauterine growth restriction [27] may be an early marker of cardiovascular risk as shown in unselected adults [28]. In our cohort NT-Pro-BNP does not seem to be informative as treated and untreated adolescents show similar values within the normal range (Table 1(b)).

\subsection{Reduced HRV Normalizes after Cessation of GH Therapy}

In later childhood there seems to be no significant difference between treated and untreated children up to the cessation of GH therapy at about 16 years of age as both show equally signs of autonomic dysfunction (Table 2). The circadian pattern of heart rate illustrated in Figure 3 shows significantly higher heart rates only at night after growth hormone injection in the evening. These results 
are in good accordance with the decline of HRV after starting GH therapy in adults [29] that would indicate a higher cardiovascular risk. However after cessation of GH therapy we found a significant increase of HRV to normal values, indicated by a decrease of heart rate and an increase of global HRV measured as SDNN (Table 3).

However this unbeneficial effect of growth hormone by lowering HRV with elevated heart rates at night seems to be completely reversible in children after cessation of growth hormone therapy. To our surprise in contrast to the low HRV in childhood we found completely normal HRV values in post pubertal young adults who had received growth hormone during childhood. This observation seems to be very important to predict the impact of growth hormone therapy in childhood on longtime cardiovascular mortality: The improvement of HRV after cessation of growth hormone therapy may be a marker for a normal cardiovascular prognosis in GH treated children. We have no data to compare HRV of untreated young adults with our group of patients after cessation of GH therapy. However adults with extremely low birth weight are reported to have reduced HRV [19] [20] but not adults with moderate low birth weight and catch up growth [30]. We speculate that induction of catch up growth in childhood may support the normalization of the autonomic nervous system in adolescence. In contrast to these pediatric data studies on adult GHD show evidence of disturbance of the glycolipid metabolism and enhanced prevalence of metabolic syndrome which is associated with increased cardiovascular risk [31] [32].

\subsection{Autonomic and Endocrine Effects of GH Treatment Seem to Summarize to Reduction of Cardiovascular Risk after Cessation of Therapy}

These data are in accordance with a recent longitudinal study investigating 199 patients after the cessation of GH replacement [33]. 5 years after cessation values for blood pressure, lipids and intima thickness were not different from adults born small for gestational age and adults with normal birth weight. A pediatric study found favorable effects of GH treatment on blood lipids and intima thickness [34]. Comparable effects were found on lipid metabolism and liver enzymes in obese children [35]. Similar positive effects have been documented on reduction of fat mass and mitochondrial function in peripheral muscles [36]. Summarizing these findings there are enhancing and ameliorating effects of $\mathrm{GH}$ treatment on cardiovascular risk. Some of them as increase of heart rate at night may be acting short term, some as reduction of blood lipids may have effects persisting for longer periods. This may explain our finding of improvement of HRV data after cessation in our patient group. Taking together these data there seems to be an improvement to the underlying increased cardiovascular risk of SySS pediatric patients after cessation of GH therapy.

\subsection{Is There a Common Link between Attention Regulation and Growth?}

The high incidence of ADHD (22 out of 106) in our patient group is remarkable 
and may have attributed to the finding of reduced HRV in patients with symptomatic short stature as there is a well described reduction of HRV in ADHD patients [23] [37]. However according to data from Rose et al. there is a similar increased number of ADHD diagnosis by 1190 out of 7230 short patients receiving GH treatment [38] suggesting some coincidence of these two diagnoses. Furthermore diagnosis of ADHD seems to be related to smaller growth velocity induced by GH treatment [38]. Keeping in mind the idea of autonomic imprinting [10] we may speculate about common pathophysiological pathways in the development of both entities. This idea is supported by the successful use of the a2A-receptor-agonist Guanfacine for treatment of ADHD according to clinical guidelines.

\section{Conclusion}

In conclusion, our new approach for assessing autonomic maturation and cardiovascular risk by 24-hour HRV analysis in children with SySS may answer the urgent question recently published in Lancet Diabetes and Endocrinology: "How concerned should we be over the long-term safety of growth hormone therapy?" [39]: There is a comparable autonomic dysfunction in treated and untreated children with short stature due to growth hormone deficiency or intrauterine growth restriction as an indicator for the enhanced cardiovascular risk. With respect to longtime prognosis, we found a significant improvement of reduced HRV to normal values after cessation of growth hormone therapy in adolescents. This finding is suggesting an improvement of cardiovascular risk in this group of patients.

\section{Limitations}

The most important limitation to our data is the small sample size which is spread over 5 different time points. Bigger specialized departments with high numbers of patients are cordially invited to work further on this subject.

\section{Acknowledgements}

We thank H. Zimmerman, C. Weiss, K. Kirchner and K.-H. Stump for technical support and 24-hour ECG recordings of the highest quality. We thank the "Blaschek foundation" who supports us by covering the publication fees for this research project. The funders had no role in study design, data collection and analysis, decision to publish, or preparation of the manuscript.

\section{Conflicts of Interest}

The authors declare no conflicts of interest regarding the publication of this paper.

\section{References}

[1] Paajanen, T.A., Oksala, N.K., Kuukasjarvi, P. and Karhunen, P.J. (2010) Short Sta- 
ture Is Associated with Coronary Heart Disease: A Systematic Review of the Literature and a Meta-Analysis. European Heart Journal, 31, 1802-1809. https://doi.org/10.1093/eurheartj/ehq155

[2] De Leonibus, C., De Marco, S., Stevens, A., Clayton, P., Chiarelli, F. and Mohn, A. (2016) Growth Hormone Deficiency in Prepubertal Children: Predictive Markers of Cardiovascular Disease. Hormone Research in Paediatrics, 85, 363-371. https://doi.org/10.1159/000444143

[3] Barker, D.J., Winter, P.D., Osmond, C., Margetts, B. and Simmonds, S.J. (1989) Weight in Infancy and Death from Ischaemic Heart Disease. The Lancet, 2, 577-580. https://doi.org/10.1016/S0140-6736(89)90710-1

[4] Adair, L.S., Fall, C.H.D., Osmond, C.O., Stein, A.D., Martorell, R. and Ramirez-Zea, M. (2013) Associations of Linear Growth and Relative Weight Gain during Early Life with Adult Health and Human Capital in Countries of Low and Middle Income: Findings from Five Birth Cohort Studies. The Lancet, 382, 525-534. https://doi.org/10.1016/S0140-6736(13)60103-8

[5] Child, C.J., Zimmermann, A.G., Chrousos, G.P., Cummings, E. and Deal, C.L. (2019) Safety Outcomes during Pediatric GH Therapy: Final Results from the Prospective GeNeSIS Observational Program. The Journal of Clinical Endocrinology \& Metabolism, 104, 379-389. https://doi.org/10.1210/jc.2018-01189

[6] Lanes, R. (2016) Cardiovascular Risk in Growth Hormone Deficiency: Beneficial Effects of Growth Hormone Replacement Therapy. Endocrinology and Metabolism Clinics of North America, 45, 405-418. https://doi.org/10.1016/j.ecl.2016.01.005

[7] Ramos-Levi, A.M. and Marazuela, M. (2017) Cardiovascular Comorbidities in Acromegaly: An Update on Their Diagnosis and Management. Endocrine, 55, 346-359. https://doi.org/10.1007/s12020-016-1191-3

[8] Sverrisdottir, Y.B., Elam, M., Herlitz, H., Bengtsson, B.A. and Johannsson, G. (1998) Intense Sympathetic Nerve Activity in Adults with Hypopituitarism and Untreated Growth Hormone Deficiency. The Journal of Clinical Endocrinology \& Metabolism, 83, 1881-1885.

[9] Willaschek, C., Meint, S., Rager, K. and Buchhorn, R. (2015) Modified Clonidine Testing for Growth Hormone Stimulation Reveals Alpha2-Adrenoreceptor Sub Sensitivity in Children with Idiopathic Growth Hormone Deficiency. PLoS ONE, 10, e0137643. https://doi.org/10.1371/journal.pone.0137643

[10] Buchhorn, R., Meint, S. and Willaschek, C. (2016) The Impact of Early Life Stress on Growth and Cardiovascular Risk: A Possible Example for Autonomic Imprinting? PLoS ONE, 11, e0166447. https://doi.org/10.1371/journal.pone.0166447

[11] Carel, J.C., Ecosse, E., Landier, F., Meguellati-Hakkas, D., Kaguelidou, F., Rey, G., et al. (2010) Long-Term Mortality after Recombinant Growth Hormone Treatment for Isolated Growth Hormone Deficiency or Childhood Short Stature: Preliminary Report of the French SAGhE Study. The Journal of Clinical Endocrinology \& Metabolism, 97, 416-425. https://doi.org/10.1210/jc.2011-1995

[12] Poidvin, A., Touze, E., Ecosse, E., Landier, F., Béjot, Y., Giroud, M., et al. (2014) Growth Hormone Treatment for Childhood Short Stature and Risk of Stroke in Early Adulthood. Neurology, 83, 780-786. https://doi.org/10.1212/WNL.0000000000000737

[13] De Bock, F., Jarczok, M.N., Hoffmann, K. and Buchhorn, R. (2013) Do Our Children Lose Vagus Activity? Potential Time Trends of Children's Autonomic Nervous System Activity. International Journal of Cardiology, 170, e30-e32. https://doi.org/10.1016/j.ijcard.2013.10.067 
[14] Task Force of the European Society of Cardiology and the North American Society of Pacing and Electrophysiology (1996) Heart Rate Variability: Standards of Measurement, Physiological Interpretation and Clinical Use. Circulation, 93, 1043-1065. https://doi.org/10.1161/01.CIR.93.5.1043

[15] Wulsin, L.R., Horn, P.S., Perry, J.L., Massaro, J.M. and D’Agostino, R.B. (2015) Autonomic Imbalance as a Predictor of Metabolic Risks, Cardiovascular Disease, Diabetes, and Mortality. The Journal of Clinical Endocrinology \& Metabolism, 100, 2443-2448. https://doi.org/10.1210/jc.2015-1748

[16] Rakow, A., Katz-Salamon, M., Ericson, M., Edner, A. and Vanpee, M. (2013) Decreased Heart Rate Variability in Children Born with Low Birth Weight. Pediatric Research, 74, 339-343. https://doi.org/10.1038/pr.2013.97

[17] Zamecznik, A., Stanczyk, J., Wosiak, A. and Niewiadomska-Jarosik, K. (2017) Time Domain Parameters of Heart Rate Variability in Children Born as Small-for-Gestational Age. Cardiology in the Young, 27, 663-670. https://doi.org/10.1017/S1047951116001001

[18] Souza, L.V., Oliveira, V., De Meneck, F., Grotti Clemente, A.P., Strufaldi, M.W. and Franco, M.D. (2017) Birth Weight and Its Relationship with the Cardiac Autonomic Balance in Healthy Children. PLOS ONE, 12, e0167328. https://doi.org/10.1371/journal.pone.0167328

[19] Mathewson, K.J., Van Lieshout, R.J., Saigal, S., Boyle, M.H. and Schmidt, L.A. (2014) Reduced Respiratory Sinus Arrhythmia in Adults Born at Extremely Low Birth Weight: Evidence of Premature Parasympathetic Decline? International Journal of Psychophysiology, 93, 198-203. https://doi.org/10.1016/j.ijpsycho.2014.04.005

[20] Mathewson, K.J., Van Lieshout, R.J., Saigal, S., Morrison, K.M., Boyle, M.H. and Schmidt, L.A. (2015) Autonomic Functioning in Young Adults Born at Extremely Low Birth Weight. Global Pediatric Health, 2. https://doi.org/10.1177/2333794X15589560

[21] Thayer, J., Yamamoto, S.S. and Brosschot, J.F. (2010) The Relationship of Autonomic Imbalance, Heart Rate Variability and Cardiovascular Disease Risk Factors. International Journal of Cardiology, 141, 122-131. https://doi.org/10.1016/j.ijcard.2009.09.543

[22] Vaseghi, M. and Shivkumar, K. (2008) The Role of the Autonomic Nervous System in Sudden Cardiac Death. Progress in Cardiovascular Diseases, 50, 404-419. https://doi.org/10.1016/j.pcad.2008.01.003

[23] Buchhorn, R., Conzelmann, A., Willaschek, C., Stork, D., Taurines, R. and Renner, T.J. (2012) Heart Rate Variability and Methylphenidate in Children with ADHD. ADHD Attention Deficit and Hyperactivity Disorders, 4, 85-91. https://doi.org/10.1007/s12402-012-0072-8

[24] Porges, S.W. (2009) The Polyvagal Theory: New Insights into Adaptive Reactions of the Autonomic Nervous System. Cleveland Clinic Journal of Medicine, 76, S86-S90. https://doi.org/10.3949/ccjm.76.s2.17

[25] Wallaschofski, H., Saller, B., Spilcke-Liss, E., Lerch, M.M., Lohmann, T. and Eigenthaler, M. (2006) Effects of Growth Hormone Treatment on B-Type Natriuretic Peptide as a Marker of Heart Failure in Adults with Growth Hormone Deficiency. Hormone and Metabolic Research, 38, 656-661. https://doi.org/10.1055/s-2006-954588

[26] Andreassen, M., Faber, J., Kjaer, A., Petersen, C.L. and Kristensen, L.O. (2011) Cardiac Function in Growth Hormone Deficient Patients before and after 1 year with 
Replacement Therapy: A Magnetic Resonance Imaging Study. Pituitary, 14, 1-10. https://doi.org/10.1007/s11102-010-0250-7

[27] Fujioka, K., Mizobuchi, M., Sakai, H., Iwatani, S., Wada, K., Yoshimoto, S. and Nakao, H. (2014) N-Terminal Pro-Brain Natriuretic Peptide Levels in Monochorionic Diamniotic Twins with Selective Intrauterine Growth Restriction. Journal of Perinatology, 34, 6-10. https://doi.org/10.1038/jp.2013.119

[28] Geng, Z., Huang, L., Song, M. and Song, Y. (2017) N-Terminal Pro-Brain Natriuretic Peptide and Cardiovascular or All-Cause Mortality in the General Population: A Meta-Analysis. Scientific Reports, 7, Article No. 41504.

https://doi.org/10.1038/srep41504

[29] Tanriverdi, F., Eryol, N.K., Atmaca, H., Unluhizarci, K., Ozdogru, I., Sarikaya, I., et al. (2005) The Effects of 12 Months of Growth Hormone Replacement Therapy on Cardiac Autonomic Tone in Adults with Growth Hormone Deficiency. Clinical Endocrinology, 62, 706-712. https://doi.org/10.1111/j.1365-2265.2005.02283.x

[30] Weitz, G., Bonnemeier, H., Sufke, S., Wellhoner, P., Lehnert, H. and Dodt, C. (2013) Heart Rate Variability and Metabolic Rate in Healthy Young Adults with Low Birth Weight. American Journal of Cardiovascular Disease, 3, 239-246.

[31] Wang, Y., Zheng, X., Xie, X., Qian, W., Zhang, L. and Ren, W. (2019) Correlation of Increased Serum Adipsin with Increased Cardiovascular Risk in Adult Patients with Growth Hormone Deficiency. Endocrine Practice, 25, 446-453.

https://doi.org/10.4158/EP-2018-0541

[32] Verhelst, J., Mattsson, A.F., Camacho-Hübner, C., Luger, A. and Abs, R. (2018) The Prevalence of the Metabolic Syndrome and Associated Cardiovascular Complications in Adult-Onset GHD during GH Replacement: A KIMS Analysis. Endocrine Connections, 7, 653-662. https://doi.org/10.1530/EC-18-0096

[33] van der Steen, M., Kerkhof, G.F., Smeets, C.C.J. and Hokken-Koelega, A.C.S. (2017) Cardiovascular Risk Factors and Carotid Intima Media Thickness in Young Adults Born Small for Gestational Age after Cessation of Growth Hormone Treatment: A 5-Year Longitudinal Study. The Lancet Diabetes and Endocrinology, 5, 975-985. https://doi.org/10.1016/S2213-8587(17)30311-X

[34] Chen, M., Gan, D., Luo, Y., Rampersad, S., Xu, L., Li, N. and Li, H. (2018) Effect of Recombinant Human Growth Hormone Therapy on Blood Lipid and Carotid Intima-Media Thickness in Children with Growth Hormone Deficiency. Pediatric Research, 83, 954-960. https://doi.org/10.1038/pr.2017.271

[35] Liang, S., Xue, J. and Li, G. (2018) (2018) Effects of Recombinant Human Growth Hormone Administration on Cardiovascular Risk Factors in Obese Children with Relative Growth Hormone Deficiency. Lipids in Health and Disease, 17, 66. https://doi.org/10.1186/s12944-018-0721-9

[36] Gonzales, S., Sathyapylan, T., Javed, Z. and Atkin, S.L. (2018) Effects of Growth Hormone Replacement on Peripheral Muscle and Exercise Capacity in Severe Growth Hormone Deficiency. Frontiers in Endocrinology, 9, 56. https://doi.org/10.3389/fendo.2018.00056

[37] Buchhorn, R., Müller, C., Willaschek, C. and Norozi, K. (2012) How to Predict the Impact of Methylphenidate on Cardiovascular Risk in Children with Attention Deficit Disorder. ISRN Pharmacology, 2012, Article ID: 170935. https://doi.org/10.5402/2012/170935

[38] Rose, S.R., Reeves, G., Gut, R. and Germak, J. (2015) Attention-Deficit/Hyperactivity Disorder Medication Treatment Impact on Response to Growth Hormone Therapy: Results from the ANSWER Program, a Non-Interventional Study. Journal of Pedia- 
trics, 167, 1389-1396. https://doi.org/10.1016/j.jpeds.2015.08.036

[39] Tritos, N.A. (2017) How Concerned Should We Be over the Long-Term Safety of Growth Hormone Therapy? The Lancet Diabetes and Endocrinology, 5, 79-81. https://doi.org/10.1016/S2213-8587(16)30423-5 